\title{
High Central Venous Pressure and Right Ventricle Size are Related to Increased Stroke Volume to Negative Fluid Balance in Critically III Patients
}

\section{Zhao Hua}

Peking Union Medical College Hospital

Xiaoting Wang ( $\nabla$ wangxiaoting@pumch.cn )

Peking Union Medical College Hospital

Liu Dawei

Peking Union Medical College Hospital

Ding Xin

Peking Union Medical College Hospital

\section{Research}

Keywords: central venous pressure, RVD/LVD ratio, fluid therapy, stroke volume

Posted Date: January 21st, 2021

DOI: https://doi.org/10.21203/rs.3.rs-149119/v1

License: (a) (i) This work is licensed under a Creative Commons Attribution 4.0 International License. Read Full License 


\section{Abstract}

\section{Background}

This study aimed to determine whether a negative fluid balance can increase stroke volume (SV) and the relationship between changes in hemodynamics variables.

\section{Methods}

This prospective study included patients with high central venous pressure (CVP) ( $\geq 8 \mathrm{mmHg}$ ) treated in the Critical Medicine Department of Peking Union Medical College Hospital. Patients were classified into two groups based on their right to left ventricle diastolic dimension $\left(R V_{D} / L V_{D}\right)$ ratio using a cutoff value of 0.6. The hemodynamic and echo parameters of the two groups were recorded at baseline and after negative fluid balance.

\section{Results}

This study included 71 patients: 35 in Group $1\left(R V_{D} / L V_{D} \geq 0.6\right)$ and 36 in Group $2\left(R V_{D} / L V_{D}<0.6\right)$. Of all patients, $56.3 \%$ showed increased $S V$ after negative fluid balance. Cox logistic regression analysis suggested that a high CVP and $R V_{D} / L V_{D}$ ratio were significant independent risk factors for $S V$ increase after negative fluid balance in critically patients without underlying cardiac disease. The AUC of CVP was 0.894. A CVP> $10.5 \mathrm{mmHg}$ provided a sensitivity of $87.5 \%$ and a specificity of $77.4 \%$. The AUC of CVP combined with the $R V_{D} / L V_{D}$ ratio was 0.926 , which provided a sensitivity of $92.6 \%$ and a specificity of $80.4 \%$.

\section{Conclusion}

High CVP and $R V_{D} / L V_{D}$ ratio were identified as independent risk factors for $R V$ volume overload in critically patients without underlying cardiac disease. A reduced intravascular volume may increase SV for these patients.

\section{Background}

In the management of hemodynamic instability, optimal adjustment of cardiac preload is essential for improving stroke volume (SV) and tissue perfusion. Fluid management in critical patients is crucial for prognosis, as both inadequate fluid or fluid overload can lead to negative outcomes[2]. In particular, fluid overload and high CVP are associated with poor outcomes[3]. Traditionally, fluid responsiveness is defined as the ability of the left ventricle (LV) to increase SV by $10-15 \%$ in response to fluid infusion [4]. However, we found that negative fluid balance can also increase SV under certain conditions in clinical practice. This is because the left and right ventricles (RV) are interdependent and interactive; thus, a change in volume and pressure load or a change in myocardial stiffness and contractility on one side may affect the ventricle on the other side[5]. Several studies have reported that fluid overload can 
increase RV size[6]. RV size is known to modify the response to fluid challenge, such that higher RV dilatation is associated with a lower likelihood of fluid responsiveness. If RV size further increases and the right to left ventricular end-diastolic dimensions $\left(R V_{D} / L V_{D}\right)$ ratio is $\geq 0.6$, the ventricular septum and pericardium may lead to a significant decrease in LV end-diastolic area and SV.

According to the understanding of fluid responsiveness, assessing the filling state of the RV is key to judging the volume status. However, evaluation of the filling state remains a challenge. Dynamic monitoring of right end-diastolic pressure and assessment of RV size via echocardiography are currently used as indices of RV filling state[7-10]. However, it is unknown whether a negative fluid balance can increase SV in patients with high CVP. Furthermore, the relationship between hemodynamic parameters and therapy outcomes are unclear. In the present study, we use our clinical database to address these questions.

\section{Methods}

\section{Study design and patient enrollment}

The primary aim of this study was to evaluate the relationship between hemodynamic parameters and VTI changes after negative fluid management in patients with high CVP. The study was designed as a prospective observational cohort study. All patients with abnormally high CVP (i.e., outside the normal range of 0-7 mmHg) treated at the Critical Medicine Department of Peking Union Medical College Hospital from May 2017 to October 2017 were included in the study sample. This study was approved by the ethics committee of Peking Union Medical College Hospital (S-617) and written informed consent was provided by the next of kin of all participants.

\section{Inclusion and exclusion criteria}

The inclusion criteria were (i) CVP $\geq 8 \mathrm{mmHg}$ and (ii) age $>18$ years. The exclusion criteria were (i) noncurative goals of therapy, (ii) a history of cardiac disease, and (iii) pulmonary hypertension or precaval malformations. Patients were divided into two groups according to $R V_{D} / L V_{D}$ ratio: Group 1 comprised patients exhibiting $R V$ dilatation $\left(R V_{D} / L V_{D}\right.$ ratio $\left.\geq 0.6\right)$ and Group 2 comprised patients without $R V$ dilatation (RV/LV ratio $<0.6)$.

\section{Study protocol}

All patients were treated as follows:

(1) All enrolled patients underwent the routine procedures of the Critical Care Department of Peking Union Medical College Hospital. Arterial and venous lines were inserted. Time 0(T0)was recorded at ICU admission, and T1 was recorded after a negative fluid balance of $500 \mathrm{~mL}$ within 30-60 minutes. Central venous and arterial blood gases analysis were performed at T0 and T1. 
(2) Critical ultrasound was also performed at T0 and T1 by competent attending physicians or fellows using an ultrasound system equipped with an array probe(X-Porte,Sonosite, Bothell[WA[USA). At least five standard views (acoustic windows) were obtained and recorded for each scan: parasternal long axis, parasternal short axis, apical four-chamber, subcostal, and inferior vena cava (IVC). The following parameters were analyzed $\square$ Figure $1 \rrbracket: R V_{D} / L V_{D}$ ratio, tricuspid annular plane systolic excursion (TAPSE), diameter of the inferior vena cava (DIVC), left ventricular eject fraction (LVEF), and left ventricular stroke volume (LVSV). LVSV was calculated by combining the averaged left ventricular outflow tract velocity time integral (LVOT VTI) by pulsed wave Doppler for the whole respiratory cycle with 2D measurement of the related diameter[11]. $R V$ size was also evaluated at end-expiration by the $R V_{D} / L V_{D}$ ratio. $R V_{D}$ and $L V_{D}$ were measured in the apical 4-CH view by identifying the maximal distance between the ventricular endocardium and the interventricular septum perpendicular to the long axis at the beginning of the QRS complex[12]. All results were confirmed by two competent attending physicians.

(3) The method of negative fluid balance (application of diuretic drugs or continuous renal replacement therapy) was determined by the physician. No changes were made to mechanical ventilation, the set of vasoactive drugs, or the sedation level ( $\Delta$ Richmond Agitation-Sedation Scale score $<1$ point).

Furthermore, no changes were made to the thoracic/abdominal pressure that may cause changes in CVP. In the case of patient hypoxia, the inhaled oxygen concentration was adjusted to ensure SP02 $>95 \%$, $\mathrm{Pa} 02>60 \mathrm{mmHg}$.

\section{Data collection}

Clinical data were extracted from the ICU computerized database and medical records, including patients' socio-demographic data, biometric parameters, comorbidities, respiratory support mode, and Acute Physiology and Chronic Health Evaluation II scores. Hemodynamic parameters (heart rate, mean arterial blood pressure, and CVP) and echo parameters (such as DIVC, $\mathrm{RV}_{\mathrm{D}} / \mathrm{LV}_{\mathrm{D}}$ ratio, LVEF, LVOT VTI, and TAPSE) were recorded at T0 and T1. Central venous oxygen saturation (ScVO2), central venous-arterial carbon dioxide difference (GAP), and serum lactate levels (lac) were also recorded at the same time. The primary outcome of the study was to clarify VTI change after negative fluid management in patients with high CVP. The secondary outcome was to evaluate the relationship between hemodynamic parameters and VTI change after negative fluid management.

\section{Statistical analysis}

Statistical analysis was performed using SPSS software version 20.0 for Windows (IBM, Armonk, NY). Results for continuous variables with a normal distribution (e.g., age, Acute Physiology and Chronic Health Evaluation II score) are reported as the mean \pm standard deviation. Student's t-test was used to compare means between two groups. Results for continuous variables that were not normally distributed are reported as the median (25th and 75th percentiles) and compared using nonparametric tests. The paired sample t-test was used for comparisons between groups before and after treatment. Cox regression models were used to measure the relative risk (RR) and $95 \% \mathrm{Cl}$ for each factor to discover how SV can increase after negative fluid balance. The correlation between RV and $\triangle \mathrm{VTI} / T O V T I$ variables was 
analyzed using Pearson correlation analysis. Receiver operating characteristic (ROC) curves were used to determine the ability of the indices to predict LVOT VTI increase $>10 \%$ after negative fluid balance. The areas under the ROC curves (AUCs) were compared using DeLong's test. The AUC, sensitivity, and specificity are expressed as values with $95 \%$ confidence intervals (Cls). A P value $<0.05$ was considered to be statistically significant.

\section{Results}

\section{Demographic and clinical characteristics of patients}

During the study period, a total of 154 patients were admitted with CVP $\geq 8 \mathrm{mmHg}$. Of these, $65 \mathrm{did}$ not meet the study criteria. In addition, nine patients were excluded due to poor TT image quality or incomplete image acquisition; six patients were excluded due to inconsistent judgments of the ultrasound results by the two physicians; and three patients were excluded due to new tachyarrhythmia during the trial. Thus, the final sample for analysis comprised 71 patients (33 males, 38 females)(Figure 2).

Of the final sample, 35 patients $(49.3 \%)$ were in Group $1\left(\mathrm{RV}_{\mathrm{D}} / \mathrm{LV} \mathrm{D}_{\mathrm{D}}\right.$ ratio $\left.\geq 0.6\right)$ and 36 patients $(50.7 \%)$ were in Group $2\left(\mathrm{RV}_{\mathrm{D}} / \mathrm{LV} \mathrm{V}_{\mathrm{D}}\right.$ ratio $\left.\otimes 0.6\right)$. Overall, 40 (56.3\%) patients showed increased VTI after negative fluid balance. The demographical and clinical characteristics of all patients are shown in Table 1. In terms of hemodynamic parameters, patients in Group 1 had a higher CVP and GAP and lower ScV02 relative to Group 2 (all $p<0.05$ ). No group differences were observed for HR, MAP, or lactate levels. Regarding the echo parameters, the $\mathrm{RV}_{\mathrm{D}} / \mathrm{LV}_{\mathrm{D}}$ ratio, DIVC, $\triangle \mathrm{VTI}$, and $\triangle \mathrm{VTI} / \mathrm{TOVTI}$ were higher, while TO VTI was lower, in Group 1 patients (all $p<0.05$ ). There were no group differences in LVEF or TAPSE. Furthermore, there were no significant differences in demographic characteristics between the two groups. 
Table 1

The demographic and clinical Characteristics of the Patients Included in This Study

\begin{tabular}{|c|c|c|c|c|}
\hline Variable & $\begin{array}{l}\text { All patients }(\mathrm{N}= \\
\text { 71) }\end{array}$ & $\begin{array}{l}\text { Group } 1(\mathrm{~N}= \\
35)\end{array}$ & $\begin{array}{l}\text { Group 2(N= } \\
36)\end{array}$ & $\begin{array}{l}P \\
\text { value }\end{array}$ \\
\hline Gender(male/female) & $71(33 / 38)$ & $35(16 / 19)$ & $36(17 / 19)$ & 0.321 \\
\hline Age(year) & $49 \pm 16$ & $47 \pm 14$ & $50 \pm 15$ & 0.334 \\
\hline APACHE II score (mean \pm SD) & $18 \pm 8$ & $19 \pm 7$ & $16 \pm 6$ & 0.478 \\
\hline \multicolumn{5}{|l|}{ Comorbidities(\%) } \\
\hline Coronary artery disease & 13 & 5 & 8 & 0.312 \\
\hline Hypertension & 28 & 16 & 12 & 0.254 \\
\hline Diabetes mellitus & 24 & 15 & 9 & 0.092 \\
\hline Choric renal failure & 12 & 8 & 4 & 0.112 \\
\hline Choric liver failure & 4 & 2 & 2 & 0.531 \\
\hline Stroke & 8 & 3 & 5 & 0.546 \\
\hline Cancer & 6 & 2 & 4 & 0.254 \\
\hline \multicolumn{5}{|l|}{ Hemodynamic parameters } \\
\hline Central venous pressure $\mathrm{CVP}(\mathrm{mmHg})$ & $11.42 \pm 2.27$ & $12.74 \pm 2.02$ & $10.14 \pm 1.70$ & $\dot{0} 001$ \\
\hline $\begin{array}{l}\text { Mean arterial blood pressure } \\
\text { MAP }(\mathrm{mmHg})\end{array}$ & $75.70 \pm 8.724$ & $75.23 \pm 8.74$ & $76.17 \pm 7.81$ & 0.635 \\
\hline Heart rate $\mathrm{HR}(\mathrm{bpm})$ & $94.06 \pm 15.86$ & $96.43 \pm 17.55$ & $\begin{array}{l}91.75 \pm \\
153.88\end{array}$ & 0.216 \\
\hline $\mathrm{GAP}(\mathrm{mmHg})$ & $5.42 \pm 1.98$ & $6.65 \pm 1.66$ & $4.23 \pm 1.48$ & $\dot{0} 001$ \\
\hline ScVO2\% & $68.44 \pm 7.71$ & $64.28 \pm 6.10$ & $72.49 \pm 6.97$ & $\dot{0} 001$ \\
\hline $\begin{array}{l}\text { Arterial blood lactate level } \\
\text { lac(mmol/l })\end{array}$ & $3.23 \pm 0.79$ & $3.41 \pm 0.80$ & $3.04 \pm 0.74$ & 0.050 \\
\hline \multicolumn{5}{|l|}{ Echo parameters } \\
\hline LVOT VTI & $18.38 \pm 2.72$ & $16.75 \pm 1.58$ & $19.95 \pm 2.67$ & $\dot{0.001}$ \\
\hline \multicolumn{5}{|c|}{ 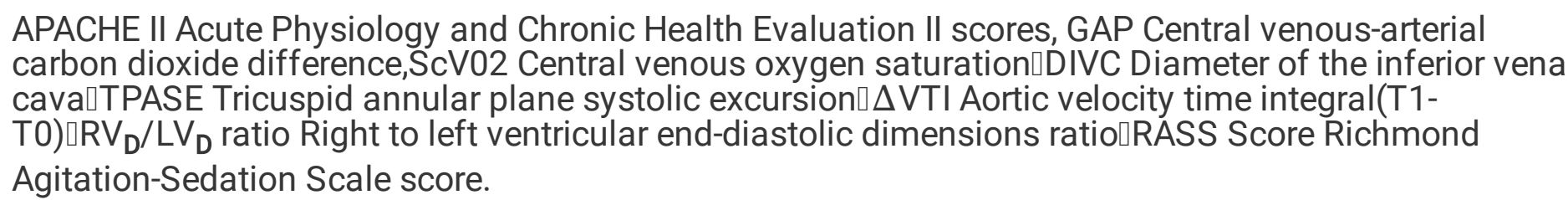 } \\
\hline
\end{tabular}




\begin{tabular}{|c|c|c|c|c|}
\hline Variable & $\begin{array}{l}\text { All patients }(\mathrm{N}= \\
\text { 71) }\end{array}$ & $\begin{array}{l}\text { Group } 1(\mathrm{~N}= \\
35)\end{array}$ & $\begin{array}{l}\text { Group } 2(\mathrm{~N}= \\
36)\end{array}$ & $\begin{array}{l}P \\
\text { value }\end{array}$ \\
\hline Left ventricular eject fraction EF \% & $62.08 \pm 5.04$ & $61.51 \pm 5.14$ & $62.64 \pm 4.94$ & 0.351 \\
\hline DIVC (cm) & $1.93 \pm 0.28$ & $2.11 \pm 0.25$ & $1.77 \pm 0.20$ & $\begin{array}{l}< \\
0.001\end{array}$ \\
\hline TAPSE $(\mathrm{cm})$ & $2.16 \pm 0.26$ & $2.15 \pm 0.28$ & $2.18 \pm 0.25$ & 0.551 \\
\hline$\Delta \mathrm{VTI}$ & $1.15 \pm 1.45$ & $1.97 \pm 1.01$ & $0.35 \pm 1.38$ & $\begin{array}{l}< \\
0.001\end{array}$ \\
\hline$\Delta$ VTI/TOVTI(\%) & $7.06 \pm 8.09$ & $11.89 \pm 5.74$ & $2.36 \pm 7.28$ & < 0.001 \\
\hline$\Delta \mathrm{VTI} / \mathrm{TOVTI}>10 \%$ & $40 / 71(56.3)$ & $27 / 31$ & $9 / 36(25)$ & $<.001$ \\
\hline $\mathrm{RV}_{\mathrm{D}} / \mathrm{LV}_{\mathrm{D}}$ ratio & $0.59 \pm 0.10$ & $0.67 \pm 0.06$ & $0.51 \pm 0.05$ & $\begin{array}{l}< \\
0.001\end{array}$ \\
\hline RASS Score & $-2.33 \pm 1.16$ & $-2.31 \pm 1.22$ & $-2.43 \pm 1.17$ & 0.674 \\
\hline \multicolumn{5}{|l|}{ Ventilation modes $\%$} \\
\hline Non-invasive ventilation & 13(18.3) & $5(14.3)$ & $6(16.7)$ & 0.256 \\
\hline Invasive ventilation & $58(81.7)$ & $30(86.4)$ & $30(83.3)$ & 0.354 \\
\hline $\mathrm{Pa02} / \mathrm{Fi} 02(\mathrm{mmHg})$ & $240.62 \pm 46.19$ & $\begin{array}{l}213.37 \pm \\
43.52\end{array}$ & $\begin{array}{l}267.11 \pm \\
31.01\end{array}$ & $\begin{array}{l}< \\
0.001\end{array}$ \\
\hline T1 to T0 Time (minute) & $50 \pm 14$ & $46 \pm 14$ & $53 \pm 16$ & 0.275 \\
\hline \multicolumn{5}{|c|}{ 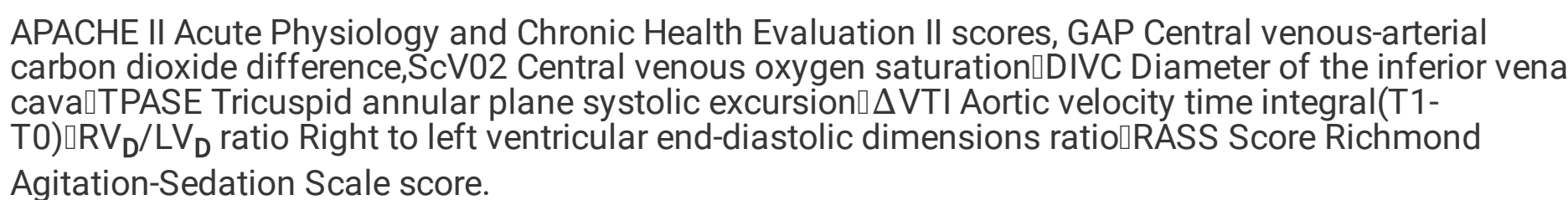 } \\
\hline
\end{tabular}

\section{Comparison of hemodynamic parameters at T0 and T1 between groups}

As shown in Fig. 3, CVP, DIVC, and $R V_{D} / L V_{D}$ ratio decreased significantly in both groups after negative fluid management $(p<0.05)$. None of the patients in our study experienced cardiac and/or tissue perfusion insufficiency. Cardiac output related parameters (LVOT VTI, GAP, ScV02) improved in Group 1 $(p<0.05)$, and the lactate level decreased in Group $2(p<0.05)$. In addition, the P/F ratio increased significantly in both groups $(p<0.05)$.

\section{Correlation between RV parameters and $\Delta \mathrm{VTI} / \mathrm{TOVTI}$}


Figure 4 presents the individual parameter values for RV and $\triangle$ VTI/TOVTI among all patients. CVP, $\mathrm{RV}_{\mathrm{D}} / \mathrm{LV}_{\mathrm{D}}$ ratio, and DIVC were significantly correlated with $\Delta$ VTI/TOVTI $(r=0.64(\mathrm{p}<0.05), 0.64(\mathrm{p}<0.053)$, and 0.59 ( $p<0.05)$, respectively). By contrast, no relationship was observed between TAPSE and $\Delta$ VTI/TOVTI.

\section{Risk factors for a LVOT VTI increase $>10 \%$ at T1}

Cox regression analysis was used to examine possible risk factors for the outcomes of negative fluid management. Each of the hemodynamics variables was taken into account. The results revealed that CVP and $R V_{D} / L V_{D}$ ratio were the most significant predictors $(p<0.05)$. The RRs of CVP and $R V_{D} / L V_{D}$ ratio were 2.425 (95\% Cl, 1.458-4.003) and 8.588 (95\% Cl, 1.947-37.887), respectively. (Table 2)

Table 2

Multifactor Cox Logistic Regression Analysis for Possible Risk Factors

\begin{tabular}{|lllllll|}
\hline Variables & B & SE & Wald's coefficient & OR & 95\% Cl for OR & p value \\
\hline CVP & & & & \multicolumn{3}{c|}{ Lower Upper } \\
\hline RV $/$ LV ratio & 2.150 & 0.757 & 8.064 & 2.425 & 1.4584 .033 & 0.001 \\
\hline CVP central venous pressure,RV & 0.260 & 11.648 & 8.588 & 1.94737 .887 & 0.005 \\
\hline
\end{tabular}

\section{Effect of risk parameters for predicting a LVOT VTI increase $>10 \%$ at $\mathrm{T} 1$}

The AUC of CVP for predicting a LVOT VTI increase > $10 \%$ at T1 was 0.883 (95\% Cl 0.804-0.902) The best diagnostic threshold was $10.5 \mathrm{mmHg}$, which provided a sensitivity of $87.5 \%$ and a specificity of 77.4\%. (Fig. 5)

The regression equation for all of the risk parameters is:

Logit $(P)=-10.474+C V P * 0.886+R V_{D} / L V_{D}$ ratio *2.854 $(\geq 0.6=1,<0.6=0)$

The AUC of CVP combined with $\mathrm{RV}_{\mathrm{D}} / \mathrm{LV}_{\mathrm{D}}$ ratio for predicting a LVOT VTI increase $>10 \%$ at T1 was 0.926 (95\% Cl 0.866-0.96). The best diagnostic threshold was 0.3689 , which provided a sensitivity of $92.5 \%$ and a specificity of $80.6 \%$. (Fig. 5)

\section{Discussion}

In the steady state, venous return is equal to cardiac output [13]; thus, right ventricular function is essential for venous return[14, 15]. The challenge of fluid management is to find the ideal preload to avoid the negative effect of ventricular interdependence on LV function and cardiac output. The right half of the heart behaves very differently from the left. Tyberg et al. [11] measured pericardial pressure and 
right atrial pressure in patients with acute excessive fluid loading before cardiopulmonary bypass. They found that these two types of pressure increased at the same rate, while the right atrial transmural pressure was unchanged. Previous studies have reported no relationship between right transmural pressure and right ventricular end-diastolic volume and stroke volume[16-18]. The healthy human RV fills at or below its unstressed volume, such that RV end-diastolic volume changes occur without any changes in RV diastolic wall stretch. Presumably, conformational changes in RV shape rather than stretch allow such volume changes to occur without measurable changes in the transmural right atrial pressure. With increased volume loading of the RV, right ventricular end-diastolic pressure and SV both increased. The relation of SV to venous return has a plateau: once this plateau is reached, any further increases in filling pressure will not augment cardiac output[19]. As a result, when RV reaches the flat part of the pressurevolume curve, the left heart no longer determines cardiac output. If the RV further increases in size and the right ventricular end-diastolic pressure rapidly increases, this can cause leftward ventricular septal (VS) shift. VS shift can result in decreased SV, leading to a phenomenon colloquially termed "falling off the Starling curve"[14] ${ }^{14141414}[14][14][14]$.

The present study is a prospective study about the relationship between hemodynamic parameters during negative fluid management. The intervention was performed in a short period of time ( $39 \pm 17$ minutes), while other factors affecting CVP were unchanged. Notably, $56.3 \%$ of our patients showed increased VTI after negative fluid balance, which is not exactly the same as the comment cognition. As the Starling curve does not have descending branches, it cannot explain the increase in SV after reducing the intravascular volume. Thus, we assume that patients experienced RV volume overload. A negative fluid balance can reduce RV volume, resulting in a rightward VS shift, an increase in left ventricular enddiastolic volume, and an increase in $\mathrm{CO}$. However, it remains unclear if determining RV volume overload is key to therapy. In terms of the hemodynamic and echo parameters in our cohort, CVP, GAP, ScVO2, RV/LV diastolic area ratio, LVOT VTI, and DIVC differed significantly between the two groups. A high $R V_{D} / L V_{D}$ ratio and CVP value were identified as risk factors for RV volume overload. Due to its geometrical complexity, assessment of RV volume is a very difficult task. Although quantitative validation is lacking, the correlation of RV linear dimensions with RV end-diastolic volumes appears to worsen with increased preload[20-22]. $R V_{D} / L V_{D}$ ratio has been shown to be an indicator of $R V$ size, and can thus provide reliable information about $\mathrm{RV}$ shape and size. A ratio $\geq 0.6$, regardless of whether $\mathrm{RV}$ is within the normal reference limits, may relate to certain conditions such as RV volume overload[20]. In our study, we found that a $\mathrm{R} / \mathrm{V}$ ratio $\geq 0.6$ was a risk factor for VTI increase after negative fluid balance. Our results are similar to those of previous studies[23]. However, our measurement method is more clinically operable and repeatable. Wiesenack et al. measured RV volume in patients with mechanical ventilation to help guide fluid resuscitation. However, in patients with pulmonary embolism and chronic pulmonary hypertension, only RVEDA/LVEDA>1 indicates RV volume overload[24, 25]. When R/V ratio is applied clinically, it should be considered in combination with the patient's underlying disease and ventricular septal morphology.

We also identified high CVP as a significant risk factor for RV volume overload. The gold standard for evaluating RV filling pressure is invasive monitoring using a centrally placed venous catheter[26]. CVP 
can be used as a surrogate of intravascular volume, and is often applied at the bedside to guide fluid administration in critically ill patients. Since the filling pressure and SV of the RV do not have a linear relationship, it has recently been acknowledged that CVP is ineffective for evaluating a patient's fluid responsiveness[27-29]. While the absolute value of CVP alone cannot predict fluid responsiveness, it is necessary to understand that CVP is a marker of pressure and a regulating factor of venous return. Thus, an increase in CVP can be used as a clinical safety mechanism to avoid fluid overload and high RV filling pressure. We consider CVP to be a safety-related indicator rather than a cardiac preload indicator in clinical settings [30]. In the present study, we found that a high CVP may reflect that the RV volume load has exceeded the normal range; failure to appreciate this limit may result in a VS rightward shift and reduced SV. It has been proposed that, once CVP has exceeded 10-14 mm Hg in non-intubated patients with acute RV myocardial infarction, further volume loading is detrimental. A mean CVP $>14 \mathrm{mmHg}$ is almost always associated with a reduced RVSWI[31, 32]. Garcia-Montilla et al. [33] reported that the optimal RV filling pressure in patients with acute respiratory distress syndrome (ARDS) is $13 \pm 2 \mathrm{~mm} \mathrm{Hg}$. Furthermore, they demonstrated that once CVP reaches $15 \mathrm{mmHg}$, further increments in filling pressure did not increase RVSPG; rather, due to overstretching of myocardial fibers, RVSPG decreased. These values may be considered the optimal RV filling pressure in patients with acute RV infarction or ARDS. Our results suggest that CVP $>10.5 \mathrm{mmHg}$ can predict whether VTI increases after a negative fluid balance in patients without underlying cardiac disease with high sensitivity but low specificity. When we combined the two risk factors, the predictive ability improved.

Notably, none of our patients experienced $\mathrm{CO}$ and tissue perfusion insufficiency after negative fluid management. However, the oxygenation index improved in both groups-especially Group 1. It is well known that fluid overload may lead to pulmonary edema and failure of weaning from mechanical ventilation. A milestone study by Wiederman et al.[34] showed that a conservative fluid management protocol aimed to lower CVP resulted in a major reduction in net fluid balance, improving lung function and shortening the duration of mechanical ventilation. Clinicians should be alert to high CVP as it may indicate increased RV tension and leftward VS, potentially leading to increased left ventricular filling pressure and pulmonary edema. Accurate fluid therapy for patients with high CVP will not lead to hypoperfusion, but will be beneficial for other organs.

Lastly, this study is subject to several limitations. Firstly, our study included a convenience sample of participants from a single institution, and may have thus systematically excluded some participant groups. As a pragmatic study, this population had similar characteristics to previous clinical audits using the same inclusion criteria. Nevertheless, additional clinical research is needed to confirm our findings. Secondly, although we excluded patients with any pre-existing heart disease based on clinical records or echocardiography, some patients might have developed subclinical heart disease after their last echocardiography. Thirdly, the determination of RV volume load may be imperfect. In our experience, estimation of RV/LV size ratio is fairly accurate, even when assessed by trainees relative to an experienced clinicians. 


\section{Conclusion}

Traditionally, RV function is thought to be of minimal relevance to overall cardiovascular homeostasis. Patients with normal cardiac function require precise fluid management to prevent a decrease in $\mathrm{CO}$ resulting from inappropriate $R V$ filling. In the present study, we identified a high CVP value and $R V_{D} / L V_{D}$ ratio as risk factors for RV volume overload. Further studies of whether precise fluid management can improve patients' 28-day mortality, shorten ICU stay, or shorten the duration of mechanical ventilation are required.

\section{Declarations}

\section{- Ethical Approval and Consent to participate}

Ethics approval and consent to participate: This study was approved by the ethics

committee of the Peking Union Medical College Hospital (S-617), and written informed consent was provided by the next of kin of all subjects .

\section{- Consent for publication}

Not applicable.

\section{- Availability of supporting data}

Not applicable.

- Competing interests

The authors declare that they have no conflicts of interest.

\section{- Funding}

Not applicable.

\section{- Authors' contributions}

X. Wang and D. Liu conceived and designed the study. H. Zhao and X. Ding were performed the ultrasound test. H. Zhao wrote the draft manuscript. D. Liu gave final approval of the version to be published. All of the authors read and approved the final manuscript.

- Acknowledgements

Not applicable. 
All the authors are come from the Department of Critical Care Medicine, Peking Union Medical College Hospital, Peking Union Medical College, Chinese Academy of Medical Sciences, 1 Shuaifuyuan, Dongcheng District, Beijing 100730, China

\section{References}

1. Acheampong $A$, Vincent $\mathrm{JL}$ : A positive fluid balance is an independent prognostic factor in patients with sepsis. Crit Care 2015, 19:251.

2. Rivers E, Nguyen B, Havstad S, Ressler J, Muzzin A, Knoblich B, Peterson E, Tomlanovich M, Early Goal-Directed Therapy Collaborative G: Early goal-directed therapy in the treatment of severe sepsis and septic shock. N Engl J Med 2001, 345(19):1368-1377.

3. Boyd JH, Forbes J, Nakada TA, Walley KR, Russell JA: Fluid resuscitation in septic shock: a positive fluid balance and elevated central venous pressure are associated with increased mortality. Crit Care Med 2011, 39(2):259-265.

4. Bentzer P, Griesdale DE, Boyd J, MacLean K, Sirounis D, Ayas NT: Will This Hemodynamically Unstable Patient Respond to a Bolus of Intravenous Fluids? JAMA 2016, 316(12):1298-1309.

5. Mitchell JR, Whitelaw WA, Sas R, Smith ER, Tyberg JV, Belenkie I: RV filling modulates LV function by direct ventricular interaction during mechanical ventilation. Am J Physiol Heart Circ Physiol 2005, 289(2):H549-557.

6. Atherton JJ, Moore TD, Lele SS, Thomson HL, Galbraith AJ, Belenkie I, Tyberg JV, Frenneaux MP: Diastolic ventricular interaction in chronic heart failure. Lancet 1997, 349(9067):1720-1724.

7. Martyn JA, Snider MT, Farago LF, Burke JF: Thermodilution right ventricular volume: a novel and better predictor of volume replacement in acute thermal injury. J Trauma 1981, 21(8):619-626.

8. Krishnan S, Schmidt GA: Acute right ventricular dysfunction: real-time management with echocardiography. Chest 2015, 147(3):835-846.

9. Puchalski MD, Williams RV, Askovich B, Minich LL, Mart C, Tani LY: Assessment of right ventricular size and function: echo versus magnetic resonance imaging. Congenit Heart Dis 2007, 2(1):27-31.

10. Dandel M, Hetzer R: Evaluation of the right ventricle by echocardiography: particularities and major challenges. Expert Rev Cardiovasc Ther 2018, 16(4):259-275.

11. Tyberg JV, Taichman GC, Smith ER, Douglas NW, Smiseth OA, Keon WJ: The relationship between pericardial pressure and right atrial pressure: an intraoperative study. Circulation 1986, 73(3):428432.

12. Rudski LG, Lai WW, Afilalo J, Hua L, Handschumacher MD, Chandrasekaran K, Solomon SD, Louie EK, Schiller NB: Guidelines for the echocardiographic assessment of the right heart in adults: a report from the American Society of Echocardiography endorsed by the European Association of Echocardiography, a registered branch of the European Society of Cardiology, and the Canadian Society of Echocardiography. J Am Soc Echocardiogr 2010, 23(7):685-713; quiz 786-688. 
13. Pinsky MR: Instantaneous venous return curves in an intact canine preparation. J Appl Physiol Respir Environ Exerc Physiol 1984, 56(3):765-771.

14. Pinsky MR: The right ventricle: interaction with the pulmonary circulation. Crit Care 2016, 20:266.

15. Takata M, Harasawa Y, Beloucif S, Robotham JL: Coupled vs. uncoupled pericardial constraint: effects on cardiac chamber interactions. J App/ Physiol (1985) 1997, 83(6):1799-1813.

16. Pinsky MR: My paper 20 years later: Effect of positive end-expiratory pressure on right ventricular function in humans. Intensive Care Med 2014, 40(7):935-941.

17. Reuse C, Vincent JL, Pinsky MR: Measurements of right ventricular volumes during fluid challenge. Chest 1990, 98(6):1450-1454.

18. Dhainaut JF, Pinsky MR, Nouria S, Slomka F, Brunet F: Right ventricular function in human sepsis: a thermodilution study. Chest 1997, 112(4):1043-1049.

19. Funk DJ, Jacobsohn E, Kumar A: The role of venous return in critical illness and shock-part I: physiology. Crit Care Med 2013, 41(1):255-262.

20. Lai WW, Gauvreau K, Rivera ES, Saleeb S, Powell AJ, Geva T: Accuracy of guideline recommendations for two-dimensional quantification of the right ventricle by echocardiography. Int $J$ Cardiovasc Imaging 2008, 24(7):691-698.

21. Haddad F, Hunt SA, Rosenthal DN, Murphy DJ: Right ventricular function in cardiovascular disease, part l: Anatomy, physiology, aging, and functional assessment of the right ventricle. Circulation 2008, 117(11):1436-1448.

22. Meyer G, Vieillard-Baron A, Planquette B: Recent advances in the management of pulmonary embolism: focus on the critically ill patients. Ann Intensive Care 2016, 6(1):19.

23. Wiesenack C, Fiegl C, Keyser A, Laule S, Prasser C, Keyl C: Continuously assessed right ventricular end-diastolic volume as a marker of cardiac preload and fluid responsiveness in mechanically ventilated cardiac surgical patients. Crit Care 2005, 9(3):R226-233.

24. Mercat A, Diehl JL, Meyer G, Teboul JL, Sors H: Hemodynamic effects of fluid loading in acute massive pulmonary embolism. Crit Care Med 1999, 27(3):540-544.

25. Fremont B, Pacouret G, Jacobi D, Puglisi R, Charbonnier B, de Labriolle A: Prognostic value of echocardiographic right/left ventricular end-diastolic diameter ratio in patients with acute pulmonary embolism: results from a monocenter registry of 1,416 patients. Chest 2008, 133(2):358-362.

26. Beigel R, Cercek B, Luo H, Siegel RJ: Noninvasive evaluation of right atrial pressure. J Am Soc Echocardiogr 2013, 26(9):1033-1042.

27. Eskesen TG, Wetterslev M, Perner A: Systematic review including re-analyses of 1148 individual data sets of central venous pressure as a predictor of fluid responsiveness. Intensive Care Med 2016, 42(3):324-332.

28. Cecconi M, Hofer C, Teboul JL, Pettila V, Wilkman E, Molnar Z, Della Rocca G, Aldecoa C, Artigas A, Jog $S$ et al: Fluid challenges in intensive care: the FENICE study: A global inception cohort study. Intensive Care Med 2015, 41(9):1529-1537. 
29. Osman D, Ridel C, Ray P, Monnet X, Anguel N, Richard C, Teboul JL: Cardiac filling pressures are not appropriate to predict hemodynamic response to volume challenge. Crit Care Med 2007, 35(1):64-68.

30. Sondergaard S, Parkin G, Aneman A: Central venous pressure: we need to bring clinical use into physiological context. Acta Anaesthesiol Scand 2015, 59(5):552-560.

31. Greyson CR: Pathophysiology of right ventricular failure. Crit Care Med 2008, 36(1 Suppl):S57-65.

32. Berisha S, Kastrati A, Goda A, Popa Y: Optimal value of filling pressure in the right side of the heart in acute right ventricular infarction. Br Heart J 1990, 63(2):98-102.

33. Garcia-Montilla R, Imam F, Miao M, Stinson K, Khan A, Heitner S: Optimal right heart filling pressure in acute respiratory distress syndrome determined by strain echocardiography. Echocardiography 2017, 34(6):851-861.

34. National Heart L, Blood Institute Acute Respiratory Distress Syndrome Clinical Trials N, Wiedemann HP, Wheeler AP, Bernard GR, Thompson BT, Hayden D, deBoisblanc B, Connors AF, Jr., Hite RD et al: Comparison of two fluid-management strategies in acute lung injury. N Engl J Med 2006, 354(24):2564-2575.

\section{Figures}






$\mathbf{a}$

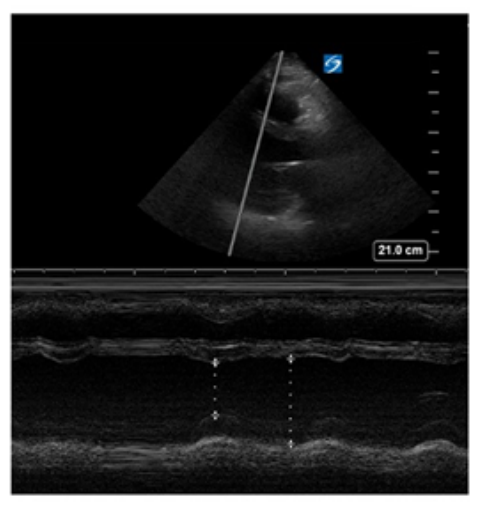

C



b

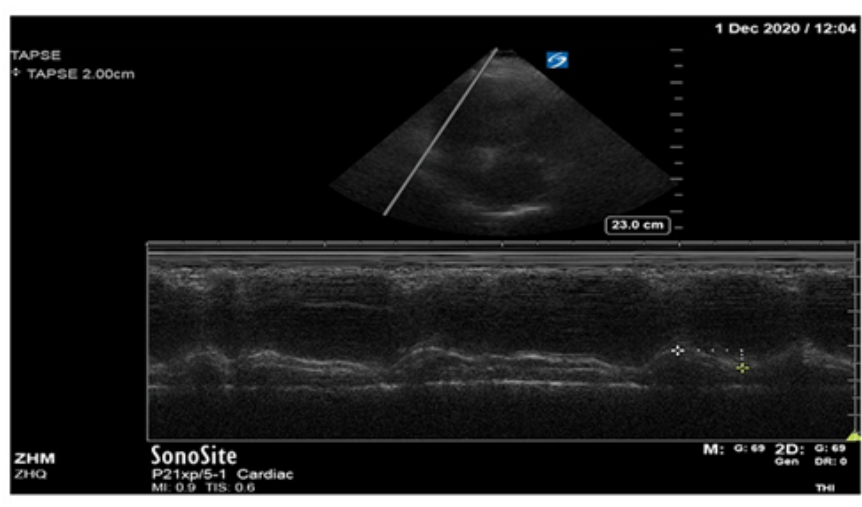

d

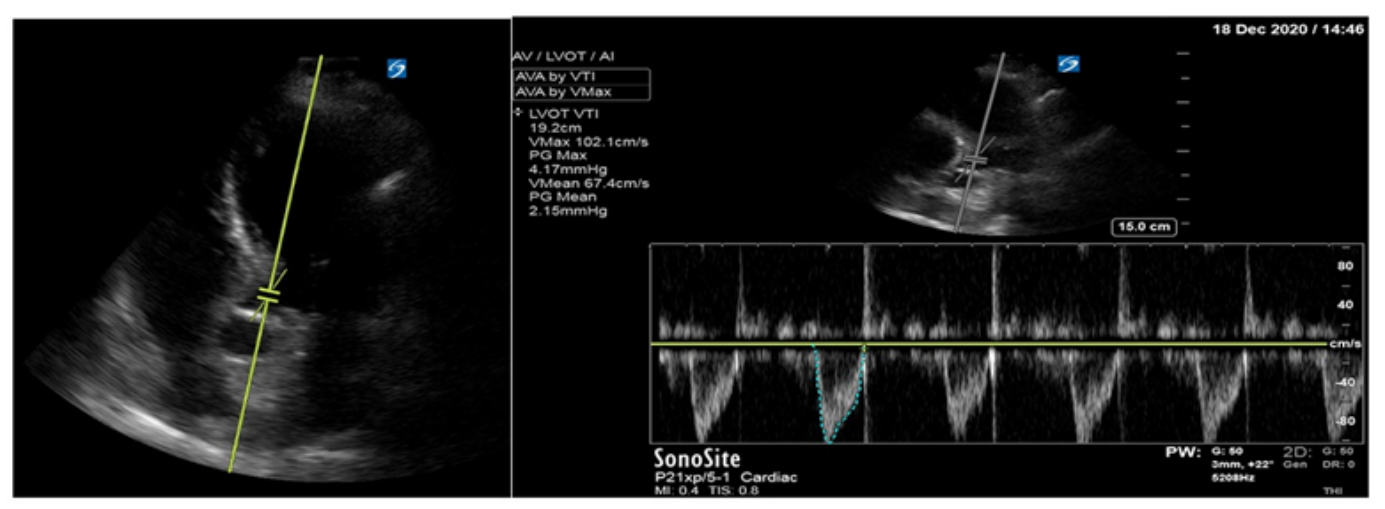

e

\section{Figure 1}

a. Right to left ventricular diastolic dimensions ratio (RVD/LVD ratio); b. Diameter of the inferior vena cava DIVC; c. Left ventricular eject fraction EF; d. Tricuspid annular plane systolic excursion TPASE; e. Velocity time integral VTI 


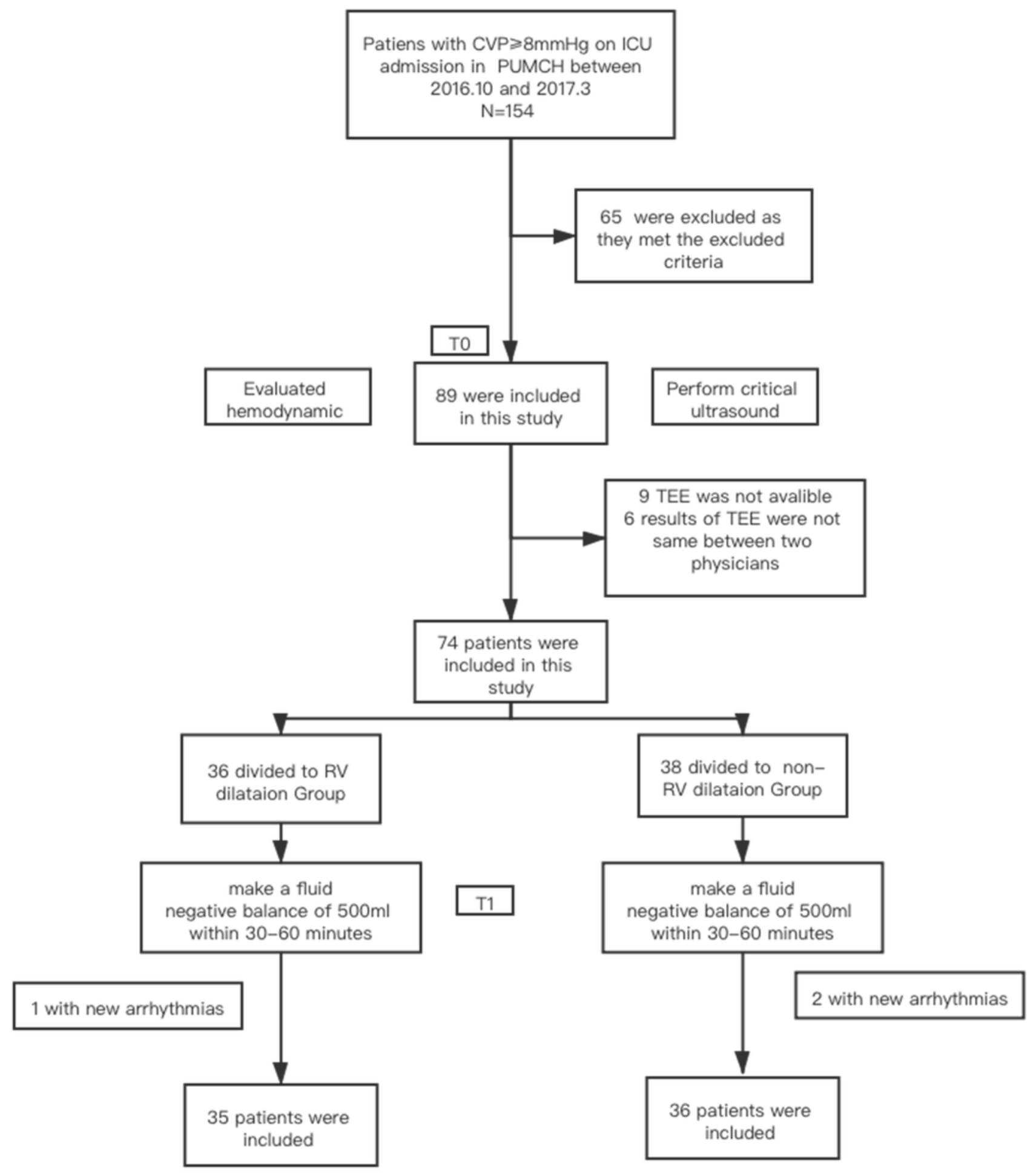

Figure 2

Flow chart 

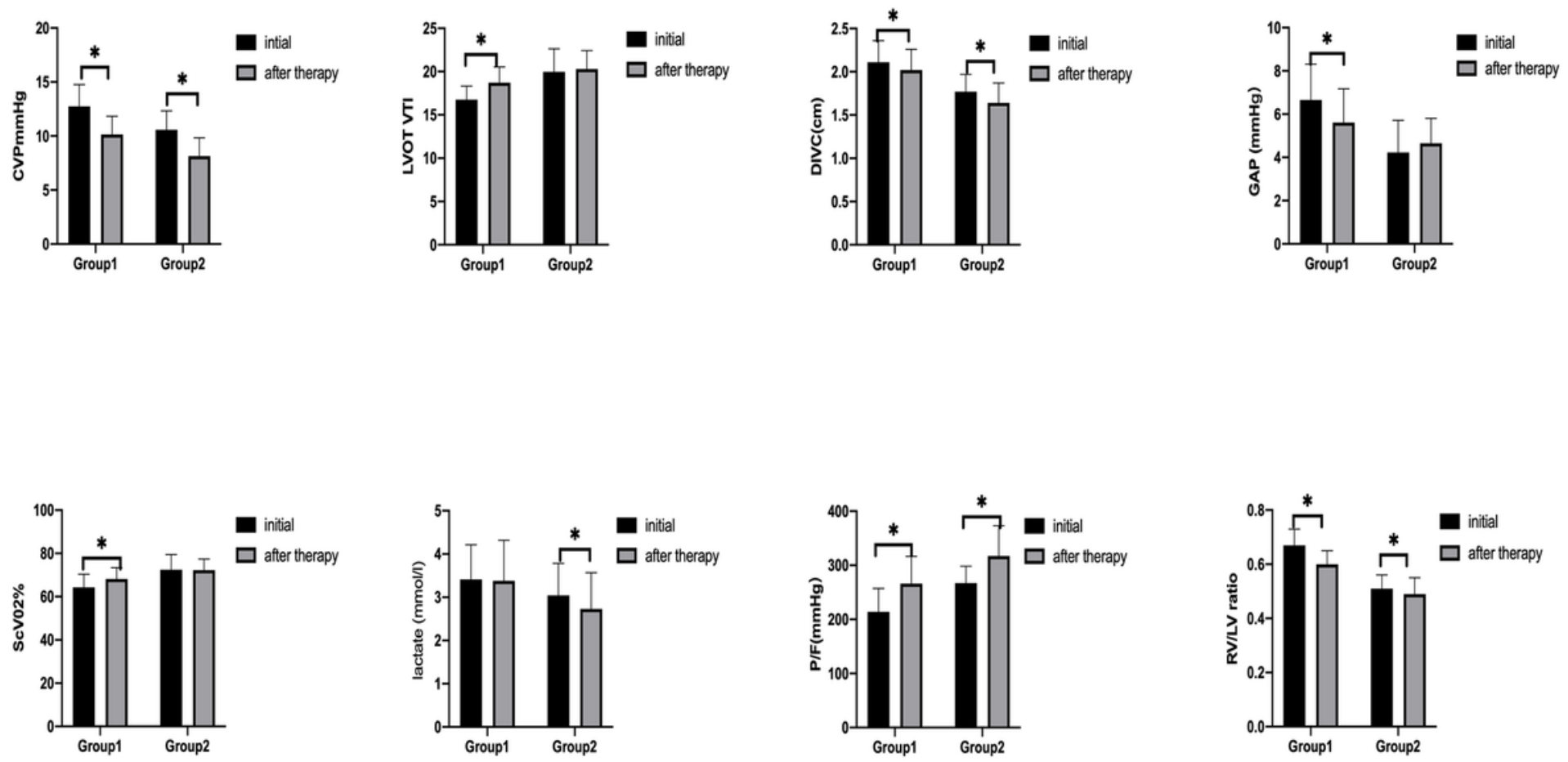

Figure 3

Hemodynamic parameters between T0 and T1 in the two groups $₫$ * indicates a $p$ value $<0.05$ between the two groups. Central venous pressure CVPQ Left ventricular outflow tract velocity time integral LVOT VTl; Diameter of the inferior vena cava DIVC; Central venous-arterial carbon dioxide difference GAPखCentral venous oxygen saturation ScVO2; Arterial partial pressure of oxygen to fractional concentration of inspired oxygen P/F; Right to left ventricular diastolic dimensions ratio RVD/LVD ratio; 

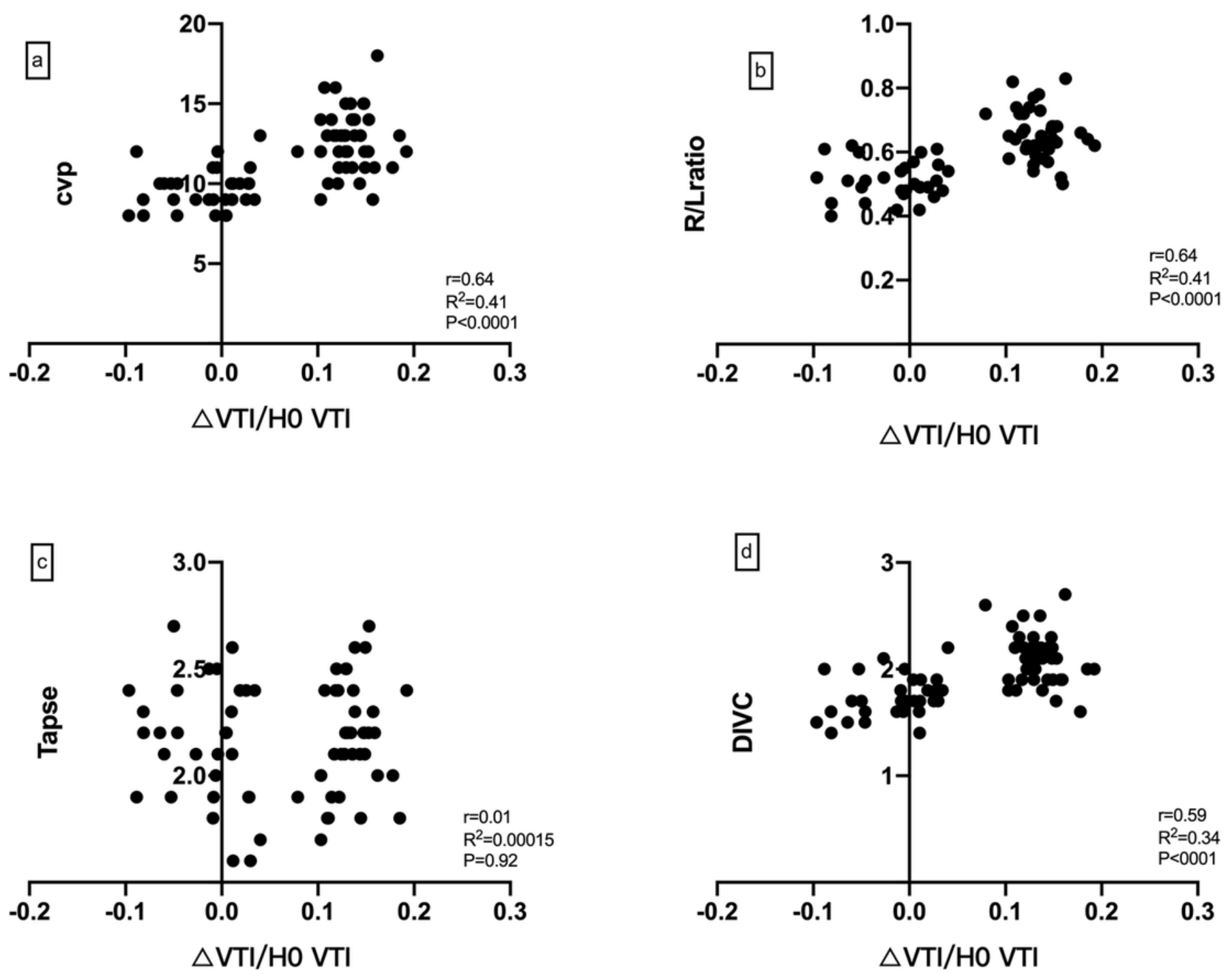

Figure 4

Correlation between $\Delta \mathrm{VTI} / \mathrm{TOVTI}$ and RV parameters, $\Delta \mathrm{VTI} / \mathrm{TOVTI}=\mathrm{T} 1 \mathrm{VTI}-\mathrm{TOVTI} / \mathrm{TO} \mathrm{VTI}$, its relationship with CVP(a), RVD/LVD ratio(b), TAPSE(c), DIVC(d). Velocity time integral VTl; Central venous pressure CVP囚Tricuspid annular plane systolic excursion TPASEखRight to left ventricular diastolic dimensions ratio $\mathrm{RVD} / \mathrm{LVD}$ ratio; Diameter of the inferior vena cava DIVC. 




\section{Figure 5}

The receiver operating characteristic (ROC) curves and the area under the ROC curve (AUC) for prediction of VTI increase after negative fluid balance. The "red model" included CVP and RVD/LVD ratio, while the "blue model" only included CVP. The AUC was 0.926 and 0.894 respectively. Velocity time integral VTI; Central venous pressure CVP; Right to left ventricular diastolic dimensions ratio RVD/LVD ratio. 